\title{
LA REALIZACIÓN DE RECONOCIMIENTOS MÉDICOS PARA LA DETECCIÓN DE COVID-19 A LOS TRABAJADORES
}

\author{
The carrying out of medical recognitions for the detection of COVID-19 \\ to workers
}

\author{
MirentXu Marín Malo*
}

Universidad Pública de Navarra, España

\begin{abstract}
RESUMEN
El presente trabajo analiza la posibilidad de realizar pruebas de carácter obligatorio a los trabajadores para la detección de sintomatología compatible con la COVID-19. El objetivo perseguido con estas pruebas es el de proteger la seguridad y salud de los trabajadores, por una parte; y evitar la propagación del virus, por otra. Para lograr el objetivo perseguido con este trabajo, se analiza la regulación relativa a la realización de reconocimientos médicos en el medio laboral, tanto en su contenido como en sus límites, dirigidos de manera especial a proteger el derecho a la intimidad recogido en el art. 18 CE. Posteriormente, se estudia el contenido del Reglamento General de Protección de Datos, haciendo especial referencia a los principios reguladores del tratamiento y a cómo limitan el uso de medios de detección de SARS-CoV-2 en las empresas.
\end{abstract}

Palabras clave: Reconocimiento médico, COVID-19, protección de datos, SARS-CoV-2, intimidad.

\section{ABSTRACT}

This article analyzes the possibility of carrying out mandatory tests on workers for the detection of symptoms compatible with COVID-19. The objective pursued with these tests is to protect the safety and health of workers, on the one hand; and prevent the spread of the virus, on the other. In order to achieve the objective pursued with this work, on the one hand, the regulations relating to the conduct of medical examinations in the workplace, both in terms of content and limits, aimed in particular at protecting the right to privacy, are analyzed. collected in art. 18 CE. Subsequently, the content of the General Data Protection Regulation is studied, making special reference to the regulatory principles of treatment and how they limit the use of SARS-CoV-2 detection means in companies.

Keywords: Medical examination, COVID-19, data protection, SARS-CoV-2, privacy.

\footnotetext{
* Correspondencia a: Mirentxu Marín Malo. Edificio las Encinas, c/ Cataluña s/n, UPNA - Campus de Arrosadia, 31006-PamplonaIruñea (España) - mirentxu.marin@unavarra.es - https://orcid.org/0000-0002-9081-6155

Cómo citar: Marín Malo, Mirentxu. (2020). «La realización de reconocimientos médicos para la detección de COVID-19 a los trabajadores"; Lan Harremanak, 43, 216-243. (https://doi.org/10.1387/lan-harremanak.21748).

Recibido: 22 mayo, 2020; aceptado: 16 junio, 2020.

ISSN 1575-7048 - eISSN 2444-5819 / (c) 2020 UPV/EHU
} 


\section{Introducción}

Es indudable que los acontecimientos acaecidos en los últimos meses suponen un cambio de paradigma social que afecta, de manera directa, al ámbito laboral. La detección, por primera vez, del SARS-CoV-2 en la ciudad de Wuhan y su rápida expansión por todo el mundo ha provocado un cambio sustancial, no solo en la forma de vida de muchas comunidades, sino también en la manera en que los servicios laborales son prestados.

En el medio laboral, el cambio ha tenido un impacto importante en dos aspectos. En primer lugar, la capacidad del sistema laboral de generar empleos y mantenerlos se ha visto reducida como consecuencia de la crisis sanitaria generada con la expansión del SARS-CoV-2. En segundo lugar, la presencia del virus en el medio laboral supone un nuevo riesgo al que se debe hacer frente desde la prevención de riesgos laborales. Ello se pone de manifiesto, no solo en la forma de proceder de las empresas, que han tomado medidas como la reorganización de los turnos para evitar aglomeraciones de personas o dotar de EPIS frente al contagio a todos los trabajadores. En esta línea, desde la propia autoridad sanitaria y laboral, se recoge, en diferentes documentos oficiales, la importancia que la actuación de los servicios de prevención de las empresas tiene para evitar la propagación del SARS-CoV-2 entre la población (Ministerio de Sanidad-Instrucciones, 2020:3).

En el escenario de la lucha contra la pandemia, y ante el criterio del Ministerio de Sanidad que establece que el objetivo debe ser «la detección precoz de cualquier caso que pueda tener infección activa y que, por tanto, pueda transmitir la enfermedad" (Ministerio de Sanidad-Instrucciones, 2020:2), así como en el marco de la obligación empresarial de proteger la seguridad y salud de los trabajadores, las empresas están realizando pruebas a los trabajadores, generalmente de carácter obligatorio, dirigidas a la detección de sintomatología compatible con la COVID-19. El objetivo de estas pruebas es el de aislar a aquellos trabajadores que presenten síntomas, impidiendo su acceso al centro de trabajo, para evitar la propagación del virus entre la plantilla y, por tanto, entre la sociedad en su conjunto.

Como se señalaba, el propio Ministerio de Sanidad ha solicitado que los servicios médicos de las empresas participen en la detección precoz de posibles casos de COVID-19, sin embargo, puesto que estas pruebas se realizan en el marco de una relación laboral, deben respetar lo establecido en el art. 22 LPRL respecto a los reconocimientos médicos con fines preventivos. Por ello, la primera parte de este estudio está centrada en determinar el encaje legal que tendría la realización de reconocimientos médicos obligatorios a los trabajadores con la finalidad señalada. Téngase en cuenta que, con independencia de la prueba realizada — que podrá resultar más o menos intrusiva respecto al derecho a la inti- 
midad del trabajador, recogido en el art. $18 \mathrm{CE}$ - el dato que se obtendrá estará relacionado con su salud, pues supondrá la sospecha o confirmación de que este está infectado o no. Por ello, al tratarse de datos relativos a la salud del trabajador, deberá aplicarse el ya citado art. 22 LPRL.

Por otra parte, el Reglamento General de Protección de Datos, así como la Ley Orgánica 3/2018, de 5 de diciembre de Protección de Datos Personales y Garantía de los Derechos Digitales, mantienen su eficacia, pues ninguna normativa aprobada para la limitación de derechos durante la crisis sanitaria ha actuado sobre el mismo. Así, el contenido de dicho Reglamento también debe ser tenido en cuenta a la hora de analizar la posible realización de reconocimientos médicos en el medio laboral dirigidos a la prevención del contagio por SARS$\mathrm{CoV}-2$ en las empresas. Al análisis de esta cuestión se dedicará una segunda parte del artículo.

En esta parte debe tenerse en cuenta, en primer lugar, que el Reglamento establece que los datos relativos a la salud son datos especialmente protegidos. Así, no basta solo con que se cumplan las condiciones establecidas en el art. 6 RGPD para que el tratamiento sea lícito; sino que, además, deberá atenderse a una de las circunstancias que permiten el tratamiento de datos personales de carácter especial de las establecidas en el art. 9 RGPD. Por último, y una vez visto el encaje legal del tratamiento de estos datos, debe atenderse a los principios que deben regir dicho tratamiento, y que establece el Reglamento en su art. 5. Para ello, se analizarán estos principios y se señalará como deben ser aplicados en la actual situación de emergencia sanitaria.

Finalmente, se recogerán las principales conclusiones extraídas tras el estudio de la normativa de aplicación y el análisis de cómo estas cuestiones afectan a la realización de pruebas a los trabajadores en estos momentos, señalando, por una parte, los requisitos que debe reunir la prueba, para dar cumplimiento a la normativa preventiva y, por otra, cómo debe realizarse el tratamiento de los datos obtenidos con objeto de no incumplir la normativa relativa a la protección de datos de carácter personal.

\section{La obligación empresarial de proteger la seguridad y salud de los trabajadores frente a la COVID-19. Uso de reconocimientos médicos como medida preventiva}

La aparición, así como la rápida expansión del SARS-CoV-2 entre la población, supone un reto en materia de prevención de riesgos laborales en el ámbito laboral. El entorno laboral es, en estos momentos, un importante foco de posible propagación del virus. Además, debido a la virulencia que la COVID-19 muestra en su desarrollo, el posible contacto con una persona infectada supone 
un riesgo importante que, en el ámbito laboral, debe ser tenido en cuenta en materia de prevención de riesgos laborales.

El art. 14 LPRL establece el derecho de las personas trabajadoras a «una protección eficaz en materia de seguridad y salud en el trabajo", lo que supone el deber empresarial de protegerlas frente a los riesgos laborales mediante la adopción de «cuantas medidas sean necesarias para la protección de la seguridad y salud de los trabajadores». Por ello, el SARS-CoV-2 debe ser tratado como riesgo laboral, en tanto que puede afectar a la salud de las personas trabajadoras.

El deber general de seguridad establecido en el art. 14 LPRL supone la obligación empresarial de facilitar a sus empleados y empleadas medios de protección suficientes que eviten el contagio en el trabajo, entendiendo que se debe perseguir el máximo nivel de seguridad posible mediante la implantación de todas las medidas preventivas que la técnica permita (Camas Roda, 2002: 77). Así, tal como el Tribunal Supremo ha señalado, el derecho a la integridad física de los trabajadores y a una adecuada política de prevención de riesgos laborales supone un derecho básico del trabajador, recogido en los arts. 4.2 y 19.2 TRET.

Por todo lo anterior, el empresario deberá tomar medidas preventivas dirigidas a controlar y evitar la expansión del SARS-CoV-2 en la empresa, dando así cumplimiento a su obligación de proteger la seguridad y salud de los trabajadores establecida en el art. 14 LPRL.

\subsection{La posible obligatoriedad del reconocimiento médico en la lucha contra el SARS-CoV-2}

Dentro de las diferentes medidas que la empresa puede adoptar para evitar la propagación del virus entre su plantilla, se encuentra la realización de reconocimientos médicos en el trabajo que establece el art. 22 LPRL. En la actual situación, el propio Ministerio de Sanidad ha reconocido la importancia que la detección precoz de la infección tiene en la lucha contra la pandemia, haciendo especial referencia a la importancia que los servicios de prevención de las empresas tienen en esta detección, pues, tal como seńalan, «están llamados a colaborar con las autoridades sanitarias en la detección precoz de todos los casos compatibles con COVID-19 para controlar la transmisión» (Ministerio de Sanidad-Instrucciones, 2020:3). Así pues, estos reconocimientos médicos están resultando de gran utilidad en la lucha contra la pandemia, pues se realizan con el objetivo de detectar síntomas de la COVID-19, de manera que se evita contacto de posibles infectados con el resto de la plantilla, siguiendo lo establecido en el Procedimiento de actuación para los servicios de prevención de riesgos laborales frente a la exposición al SARS-CoV-2 (Ministerio de Sanidad-Procedimiento, 2020:8 y ss.). Sin embargo, cabe preguntarse si el uso de reconocimientos médicos obligatorios y generalizados en esta situación está realmente justificado y amparado por la normativa. 
El art. 22 LPRL establece que «el empresario garantizará a los trabajadores a su servicio la vigilancia periódica de su estado de salud en función de los riesgos inherentes al puesto de trabajo». Por tanto, el objetivo que persiguen estos reconocimientos médicos es doble: por una parte, comprobar que el trabajador se encuentra en condiciones adecuadas para desempeñar su trabajo sin suponer y riesgo y, por otra, asegurar que el trabajo no causa ningún daño en la salud del trabajador (en este sentido, Goñi Sein y Rodríguez Sanz de Galdeano, 2014:292).

Así, la vigilancia de la salud y, por tanto, la realización de reconocimientos médicos en el trabajo se regula como un derecho del trabajador, no como una obligación. Puesto que se trata de un derecho del trabajador, el principio general que debe regir estos reconocimientos médicos es el de la voluntariedad. Por ello, y salvo excepciones, deberá contarse siempre con el consentimiento del trabajador previo a su realización.

Sin embargo, y pese a que la voluntariedad sea la norma general establecida en el propio precepto, el propio art. 22.1 LPRL, recoge tres posibles excepciones que permiten la realización de reconocimientos médicos obligatorios: a) cuando la realización del reconocimiento médico sea imprescindible para evaluar los efectos de las condiciones de trabajo en la salud del trabajador; b) cuando sea necesario para verificar si el estado de salud del empleado constituye un riesgo para su propia salud o para la salud de terceros y c) cuando lo disponga una normativa. En todo caso, tal y como han señalado numerosos autores, estas excepciones «no deben usarse de forma abusiva, pues se trata de hechos excepcionales que no pueden generalizarse» (Villalobos Cabrera, et. al.; 2019:308).

Por tanto, para que la realización de pruebas de manera generalizada para la detección de sintomatología compatible con la COVID-19 pueda realizarse de manera obligatoria para los trabajadores, deberá ampararse en una de las excepciones señaladas. Respecto a la primera opción, cuando sea imprescindible para evaluar los efectos de las condiciones de trabajo en la salud del trabajador, no es una opción. Lo que pretenden estos reconocimientos médicos no es comprobar cómo el trabajo afecta a la salud del trabajador, sino impedir que un posible infectado esté en contacto con otros compañeros durante la jornada laboral, evitando así la propagación del virus entre la plantilla.

En cuanto a la tercera de las opciones, en estos momentos no hay ninguna disposición legal que disponga la obligatoriedad de este tipo de pruebas, ni en el medio laboral ni en la sociedad en general. Si bien es cierto que el Gobierno está aprobando numerosa normativa dirigida a la lucha contra la pandemia, así como a paliar los efectos que esta puede tener en la economía y la sociedad, todavía no se han tomado medidas dirigidas a la realización masiva de pruebas a la ciudadanía con el fin de evitar la propagación del virus, y tam- 
poco se ha adoptado ninguna medida específica en el medio laboral, por lo que no procedería realizar reconocimientos médicos obligatorios al amparo de esta excepción.

Sin embargo, la segunda opción facilitada por el art. 22 LPRL dentro de las excepciones a la voluntariedad establece que, será posible la realización de reconocimientos médicos obligatorios para «verificar si el estado de salud del trabajador puede constituir un peligro para el mismo, para los demás trabajadores o para otras personas relacionadas con la empresa». Como señalan García Serrano y Pedrosa Alquezar (1999:46), lo que caracteriza a esta excepción es «la peligrosidad del estado de salud de uno de los trabajadores", que en el caso concreto y por las condiciones en que se desarrolla el trabajo, dicho estado de salud puede producir un daño en la salud de otros trabajadores o de terceras personas relacionadas con la empresa.

Así pues, la realización a los trabajadores de reconocimientos médicos obligatorios con el objetivo de detectar posibles síntomas de la COVID-19 para proceder al aislamiento de estos trabajadores y evitar la propagación del virus entre la plantilla, podrá realizarse al amparo de la excepción del art. 22 LPRL, cuando el estado de salud del empleado vinculado a aspectos laborales respecto a la organización del trabajo y prestación del servicio, pueda suponer un peligro para otros trabajadores y terceras personas relacionadas con la empresa. Sin embargo, y como se ha señalado anteriormente, la interpretación de estas excepciones debe ser restrictiva, por lo que se realizarán cuando sean realmente imprescindibles, entendiendo por ello a «aquellos supuestos en los cuales constituya el único mecanismo posible para determinar si el estado de un trabajador puede suponer un riesgo» (Fernández-Costales Muñiz, 2009:52); y así lo ha señalado el Tribunal Constitucional que establece que, para que esta obligatoriedad sea legítima no debe existir otra alternativa, diferente al reconocimiento médico, que permita comprobar si el trabajador supone un riesgo (STC 196/2004, de 15 de noviembre, FJ Sexto).

Por otra parte, en el contexto actual de emergencia sanitaria derivada de la presencia en el entorno del nuevo coronavirus SARS-CoV-2, el contenido del art. $15 \mathrm{CE}$ cobra una dimensión que abarca la necesidad de tomar medidas para evitar la propagación del virus, tanto en la sociedad en su conjunto como en el medio laboral. El art. $15 \mathrm{CE}$ reconoce el derecho de los ciudadanos a la vida y a la integridad física. Este derecho, junto con el derecho a la protección recogido en el art. 43.1 CE, así como con la obligación de los poderes públicos de tutelar la salud pública mediante la adopción de las medidas preventivas que sean necesarias (art. 43.2 CE), cobran especial interés en el momento actual. Ello, en parte, porque para proteger el derecho a la vida, la integridad física y la salud de los ciudadanos, resulta imprescindible la adopción de medidas en el medio laboral dirigidas a evitar la propagación del virus en la sociedad. Pero también por- 
que, al entrar en juego la salud pública, resulta de aplicación el art. 3 de la Ley Orgánica 3/1986 de 14 de abril, de Medidas Especiales en Materia de Salud Pública, donde se establece que

con el fin de controlar las enfermedades transmisibles, la autoridad sanitaria, además de realizar las acciones preventivas generales, podrá adoptar las medidas oportunas para el control de los enfermos, de las personas que estén o hayan estado en contacto con los mismos y del medio ambiente inmediato, así como las que se consideren necesarias en caso de riesgo de carácter transmisible.

Por lo anterior, en la situación actual que requiere de una lucha eficaz contra la pandemia, resulta necesario que la salud pública sea un bien superior a proteger por todos los agentes sociales, incluidas las empresas, aunque ello suponga la limitación de otros derechos, como puede ser en este caso, la voluntariedad del reconocimiento médico en el trabajo.

Respecto a la lucha contra la pandemia y la presencia del riesgo de contagio del SARS-CoV-2 en el medio laboral, en la actualidad, la realización de reconocimientos médicos a los trabajadores, como puede ser la toma de temperatura a la entra del centro de trabajo o la realización de pruebas serológicas y PCR para la detección del virus, están resultando ser una medida efectiva. Debe tenerse en cuenta, igualmente, que en la actualidad no existe otra alternativa, diferente a la realización de este tipo de pruebas, que permitan comprobar que el trabajador no supone riesgo de contagio para otros compañeros, por lo que el uso de estas encaja en la normativa preventiva y, además, respeta lo señalado por el Tribunal Constitucional. Como señala Goñi Sein (1999:59), «el sometimiento, en estos casos, a un reconocimiento médico obligatorio constituye un deber de solidaridad que está por encima de la libertad del individuo y se lleva a cabo por una suerte de tutela del interés colectivo».

En todo caso, y tal como ha venido señalando la doctrina, este instrumento de prevención necesita del resto de herramientas preventivas para resultar eficaz, pues, por sí solo, no protege la salud de los trabajadores de manera directa, sino que detecta el daño - en este caso la posible presencia de SARS-CoV-2 y el desarrollo de la COVID-19 por el trabajador- una vez que este ya se ha producido (entre otros: Goñi Sein, 2009:37 o Marín Malo, 2018:139). Es por que, aun realizando este tipo de pruebas al inicio de la jornada laboral, será imprescindible mantener el uso de EPIS dentro de la empresa como medida de protección frente al virus, como pueden ser mascarillas, guantes, pantallas de protección, higiene de manos, limpieza y desinfección de espacios de trabajo, tanto comunes como individuales, etc. (Ministerio de Sanidad-Procedimiento, 2020:6 y ss.). 


\subsection{Límites establecidos para el uso de reconocimientos médicos obligatorios en las empresas. Aplicación de estos límites con relación al SARS-CoV-2}

Si bien es cierto que el uso de reconocimientos médicos obligatorios en el medio laboral está amparado en una de las excepciones del art. 22 LPRL, la normativa no exime al empresario de cumplir con los límites establecidos en su regulación para que el reconocimiento médico sea considerado lícito.

Por tanto, será posible la realización de reconocimientos médicos con carácter obligatorio para los trabajadores como medida preventiva frente al posible contagio de la COVID-19 en el medio laboral siempre y cuando se respeten los límites que se detallan a continuación.

\section{a) El derecho a la intimidad como principal limite al uso de reconocimientos médicos como medida preventiva}

El principal límite a la realización de reconocimientos médicos en el medio laboral, ya sean de carácter obligatorio o voluntario, es el respeto del derecho a la intimidad recogido en el art. $18 \mathrm{CE}$. Este derecho fundamental, reconocido a todos los ciudadanos, no pierde su vigencia en el ámbito laboral, por lo que es un derecho que debe respetarse en la realización de reconocimientos médicos a los trabajadores.

El Tribunal Constitucional ha señalado que el derecho a la intimidad «implica la existencia de un ámbito propio y reservado frente a la acción y el conocimiento de los demás» (STC 196/2004, de 15 de noviembre; FJ Segundo). Ello dota al individuo del poder jurídico de impedir a terceros conocer datos personales, así como de limitar el uso y difusión de los datos conocidos.

Igualmente, debe tenerse en cuenta que «el ámbito de la intimidad corporal constitucionalmente protegido no es coextenso con el de la realidad física del cuerpo humano, porque no es una entidad física, sino cultural» (STC 196/2004, de 15 de noviembre; AH Tercero). Así, al hacer referencia al derecho a la intimidad con relación al reconocimiento médico, no se trata de proteger en exclusiva una posible actuación directa sobre el cuerpo para la recogida de muestras, sino que va más allá, y el propio conocimiento del dato de salud del trabajador, es decir, del resultado de la prueba, puede resultar una invasión del ámbito privado y reservado del individuo, protegido por el art. $18 \mathrm{CE}$.

Para salvaguardar este derecho, el Tribunal Constitucional señala que debe informarse al trabajador con carácter previo a la realización del reconocimiento médico, de las pruebas que van a realizarse y de los objetivos perseguidos con las mismas, aun cuando no se requiera el consentimiento de este (STC 196/2004, de 15 de noviembre; AH Tercero). 


\section{b) La finalidad del reconocimiento médico}

El art. 22 LPRL señala que «la vigilancia de la salud a los trabajadores se realizará en función a los riesgos inherentes al trabajo». De lo anterior se desprende que la realización de pruebas debe estar vinculada de manera directa con los riesgos a los que el trabajador está expuesto en su lugar de trabajo. Así, la única finalidad legítima del reconocimiento médico será «el conocimiento de las relaciones entre el riesgo laboral y la causa de la enfermedad del trabajador» (Camas Roda, 2002:162).

Dicho de otro modo, el reconocimiento médico será legítimo siempre y cuando cumpla dos condiciones en relación a la finalidad: que esté vinculado a un riesgo presente en el medio laboral que pueda provocar daños en la salud del trabajador en concreto, y que su única finalidad sea el conocimiento de la vinculación entre el trabajo realizado y el daño en la salud, nunca con finalidades selectivas, sancionadoras o cualquier otra que pudiera incurrir en discriminación del trabajador derivada de su estado de salud.

Tal como señala el Tribunal Constitucional, el reconocimiento médico no es «un instrumento del empresario para un control dispositivo de la salud de los trabajadores», ni tampoco "una facultad que se le reconozca para verificar la capacidad profesional o aptitud física de sus empleados» con objeto de selección de personal o promoción (STC 196/2004, de 15 de noviembre; FJ Séptimo. Se trata de un derecho del trabajador dirigido a la protección de su salud en el medio laboral, por lo que la única finalidad posible será la de prevenir un riesgo laboral; en este caso, el contagio por SARS-CoV-2 en el trabajo.

Así pues, la finalidad del reconocimiento médico en la lucha contra el SARS-CoV-2 está justificada, siempre y cuando exista riesgo real de contagio y los resultados obtenidos no sean utilizados por el empresario para tomar medidas que nada tengan que ver con la prevención de riesgos laborales y la protección de la salud de los trabajadores a su servicio.

\section{c) La proporcionalidad de las pruebas realizadas como limite a la vigilancia de la salud}

El ya citado art. 22.1 LPRL establece que «se deberá optar por la realización de aquellos reconocimientos o pruebas que causen las menores molestias al trabajador y que sean proporcionales al riesgo». El límite a la proporcionalidad que aquí se establece está vinculado, de manera directa, con el concepto de finalidad señalado en el apartado anterior. Así, en función de la finalidad perseguida se deberá optar por la prueba que cause menos molestias al trabajador, lo que determinará la proporcionalidad de estas. Igualmente, al seleccionar la prueba que cause las menores molestias al trabajador, se estará protegiendo también su derecho a la intimidad (en este sentido, GOÑI SEIN, 2009:58). 
Por su parte, el Tribunal Constitucional ha señalado que, para respetar la proporcionalidad de la prueba, se deberán cumplir las siguientes condiciones: a) seleccionar la prueba idónea en función del riesgo que se pretende evitar; b) realizar las pruebas estrictamente necesarias e indispensables con relación a la finalidad perseguida; c) seleccionar aquellas pruebas que resulten menos intrusivas para el trabajador, atendiendo a protocolos específicos; y d) su realización será siempre función del personal sanitario.

De lo anterior se extrae que, puesto que la finalidad debe estar vinculada, de manera directa, con un riesgo inherente al puesto de trabajo, y que la proporcionalidad de la prueba dependerá de la finalidad perseguida, no será posible la realización de reconocimientos médicos para la detección de síntomas de la COVID-19 cuando, por las propias características del puesto de trabajo ocupado o por la forma en que el trabajo está organizado dentro de la empresa, no exista riesgo de contagio (en este sentido, STC 196/2004, de 15 de noviembre; FJ Décimo). Esto sucederá, por ejemplo, en empresas en las que los trabajadores no comparten espacio durante la prestación del servicio, permaneciendo aislados unos de otros y donde tampoco se comparten zonas de uso común como vestuarios, baños, comedores, etc. Ejemplo de ello puede ser el gruista de una obra de construcción que no accede a zonas comunes y desarrolla su jornada completamente aislado del resto de empleados, pues se encuentra dentro de la cabina de control de la grúa, sin contacto directo con sus compañeros. Puesto que el riesgo de contagio aquí resulta mínimo, no será necesaria la realización de reconocimientos médicos, aunque sí la toma de otras medidas preventivas.

Igualmente, solo cuando no sea posible adoptar medidas preventivas suficientes de aislamiento y distanciamiento social entre las personas trabajadoras $\mathrm{o}$, cuando aun tomándolas, sea posible que estas resulten insuficientes para evitar el contagio por la forma en que se realiza la prestación del servicio y teniendo en cuenta la organización del trabajo en la empresa, será procedente realizar tomas de temperatura obligatorias y generalizadas a los empleados respetando el límite de la proporcionalidad aquí reseñado.

\section{d) El personal médico como único habilitado para la realización de la prueba y la confidencialidad de los datos obtenidos}

El art. 22.6 LPRL establece expresamente que los reconocimientos médicos deberán ser realizados «por personal sanitario con competencia técnica, formación y capacidad acreditada». Igualmente, el Ministerio de Sanidad ha señalado que

la realización de pruebas diagnósticas para la detección del COVID-19 deberá ser prescrita por un facultativo de acuerdo con las directrices, instrucciones y criterios acordados al efecto por la autoridad sanitaria competente. (Ministerio de SanidadInstrucciones, 2020:2) 
También en este sentido se ha manifestado la Agencia Española de Protección de Datos (en adelante, AEPD) al señalar que

verificar si el estado de salud de las personas trabajadoras puede constituir un peligro para ellas mismas, para el resto del personal o para otras personas relacionadas con la empresa constituye una medida relacionada con la vigilancia de la salud de los trabajadores que, conforme a la LPRL, resulta obligatoria para el empleador y debería ser realizada por personal sanitario. (AEPD-FAQs, 2020:4)

Por tanto, será el personal sanitario del Servicio de Prevención, propio o ajeno de la empresa, el encargado de la realización de las pruebas, no pudiendo ser realizadas, en ningún caso, por personal no sanitario u otros trabajadores de la empresa.

Como ya se ha señalado, el Ministerio de Sanidad ha puesto de manifiesto, en su documento Instrucciones sobre la realización de pruebas diagnósticas para la detección del COVID-19 en el ámbito de las empresas, la importancia que cobra el personal de los servicios de prevención en la lucha contra la expansión del virus, en concreto, en el ámbito laboral. Señala así que «en el escenario actual, la intervención de los servicios de prevención frente a la exposición al SARS-CoV-2, en el ámbito de las empresas es crucial» (Ministerio de Sanidad-Instrucciones, 2020:3) para frenar la expansión de este.

En cuanto a la confidencialidad respecto a los datos obtenidos en el reconocimiento médico, se establece como límite en varios apartados del art. 22 LPRL. Así, su apartado segundo señala que los reconocimientos médicos se realizarán respetando siempre «la confidencialidad de toda la información relacionada con su estado de salud». Igualmente, el apartado 3 hace referencia a que esta información solo será comunicada al trabajador afectado. Por último, el apartado 4 establece que

el acceso a la información médica de carácter personal se limitará al personal médico y a las autoridades sanitarias que lleven a cabo la vigilancia de la salud de los trabajadores, sin que pueda facilitarse al empresario o a otras personas sin consentimiento expreso del trabajador.

Por lo anterior, queda claro que el resultado de la prueba solo podrá ser conocido por el trabajador afectado, sin ser comunicado ni a la empresa ni al resto de compañeros.

Cabe plantearse si, en la actual situación de pandemia, este derecho a la intimidad y a la confidencialidad relativa a los datos de salud del empleado podría quedar supeditado al interés general de proteger la salud de terceros. A este respecto, Goñi Sein señala que «el interés general de protección de la salud de los trabajadores no es, desde luego, causa legítima que pueda justificar 
la revelación al empresario de dichos datos» (Goñi Sein, 2009:61). Está claro, pues, que no se deberán facilitar al empresario los datos específicos obtenidos en el reconocimiento médico. En cuanto al resto de trabajadores, tampoco se justificaría facilitar a estos datos relativos a la salud de un compañero de manera genérica. Sin embargo, la presencia del SARS-CoV-2 y las medidas recomendadas por las autoridades sanitarias para su control, señalando como la más efectiva el aislamiento de la persona contagiada o con síntomas y de aquellas personas que hayan estado en contacto directo con esta, supone una injerencia con relación a la confidencialidad de los datos obtenidos en el reconocimiento médico.

Ello se debe a dos causas principales. En primer lugar, resulta difícil asegurar la confidencialidad de los datos relativos a la salud - en concreto la presencia de fiebre o no- en la situación actual, por la forma de realizar la toma de temperatura - a través de carpas a la entrada del centro o con cámaras infrarrojos para lecturas masivas de temperatura-. Estos sistemas que están siendo aplicados en las empresas suponen la inexistencia de un espacio cerrado para su realización, y la toma de temperatura se realiza junto al resto de sus compañeros y compañeras. Así, en caso de mostrar una temperatura inadecuada e impedírsele la entrada al centro de trabajo, la información de que este ha presentado síntomas será conocida por el resto de trabajadores (AEPD-Comunicado, 2020:1). Pero, además, puesto que está en juego la seguridad y salud de otras personas trabajadoras y la alta transmisión del virus, con objeto de proteger la salud del resto de trabajadores, el servicio de prevención deberá informar a todos aquellos que hayan tenido contacto directo con el trabajador infectado para que tomen precauciones especiales respecto al control de síntomas y dirigidas a evitar la propagación del virus.

Por último, debe señalarse que el personal médico encargado de la prueba y, por tanto, conocedor de su resultado, tiene la obligación de notificar — con la mayor brevedad posible - a la autoridad sanitaria competente de la comunidad autónoma donde esté ubicado, los casos de COVID-19 confirmados a través de las pruebas practicadas, tal como establece la Orden SND/344/20220, de 13 de abril.

\subsection{La obligación del trabajador de velar por su salud y la de sus compańeros. Una revisión del contenido del art. 29 LPRL con relación al SARS-CoV-2}

La situación actual plantea otra cuestión de gran importancia en el medio laboral: si el trabajador está obligado o no a informar a la empresa sobre su estado de salud, con relación a la COVID-19, como medida de prevención de la expansión del virus.

El art. 29.1 LPRL establece que el trabajador deberá velar, según sus posibilidades, "por su propia seguridad y salud en el trabajo y por la de aquellas 
otras personas a las que pueda afectar su actividad profesional». La jurisprudencia ha señalado que «la salud de la persona forma parte del ámbito de su intimidad personal, lo que faculta a dicha persona para excluir dicho ámbito de la acción y conocimiento de los demás» (STSJ Castilla y León, 21 de marzo de 2005; FD Cuarto). Sin embargo, y como establece la Ley 41/2002 de 14 de noviembre, reguladora de la Autonomía del Paciente y de Derechos y Obligaciones en Materia de información y documentación Clínica, los pacientes deben facilitar información veraz sobre su estado de salud al personal médico.

Si se interpreta esta normativa atendiendo a la situación actual, debe señalarse que, la presencia del SARS-CoV-2 en las empresas no se trata tan solo de un riesgo laboral, sino que se trata de una pandemia que afecta a la población en general y que ha supuesto un estado de emergencia sanitaria sin precedentes. Como ya se ha señalado con relación a la obligatoriedad del reconocimiento médico, se trata de proteger la salud pública en general, y no tan solo la salud de los trabajadores.

Por ello, en estas especiales circunstancias, el trabajador estará obligado a informar al personal médico de la empresa sobre la presencia de síntomas compatibles con la COVID-19, con objeto de que desde el servicio médico se puedan tomar las medidas oportunas para evitar su propagación entre los trabajadores. Esto no implica que deba informar al empresario, pues la normativa solo habla del deber de informar la personal médico, por lo que, respecto al empresario, el trabajador no tiene ninguna obligación de facilitarle dichos datos relativos a su salud. Tal como señala la STSJ Castilla y León, 21 de marzo de 2005, el trabajador no está obligado a facilitar esta información al empresario, así como los servicios de prevención y personal médico, que tampoco facilitará dicha información más allá de lo estrictamente necesario para la adopción de las medidas preventivas adecuadas (STSJ Castilla y León, 21 de marzo de 2005; FD Cuarto).

\section{Los datos de salud como dato personal especialmente protegidos y la posibilidad de su tratamiento por la empresa}

Como se ha señalado anteriormente, siempre y cuando se respeten los límites que el art. 22 LPRL establece para la realización de reconocimientos médicos, y más aún, cuando su objetivo está directamente vinculado a la protección de la salud pública en general, como es el caso, pues lo que se pretende es evitar la propagación del SARS-CoV-2 entre la población, la realización de pruebas dirigidas a conocer si un trabajador presenta síntomas compatibles con la COVID-19, así como a comprobar si efectivamente, es portador del virus, están justificadas en la normativa preventiva. 
Sin embargo, puesto que se trata un dato que forma parte del ámbito privado y reservado del individuo, protegido de manera especial por el art. $18 \mathrm{CE}$, la obtención de esta información supone un tratamiento de datos de carácter personal que debe ser analizada a la luz del Reglamento General de Protección de Datos (en adelante, RGPD).

El RGPD establece, en su Considerando 46 que «el tratamiento de datos personales debe considerarse lícito cuando sea necesario para proteger un interés esencial para la vida del interesado o la de otra persona física», y añade que ciertos tipos de tratamiento pueden responder a motivos importantes de interés público, incluido el control de epidemias y su propagación. Así, ya desde el inicio del Reglamento se pone de manifiesto que el tratamiento de datos con el objetivo actualmente perseguido es legítimo, y así lo ha señalado la Agencia Española de Protección de Datos (en adelante, AEPD) en su Informe sobre la protección de datos en la actual situación de pandemia, (AEPDInforme, 2020: 1).

Se debe señalar que, según lo dispuesto en el art. 4 RGPD, se entenderá por «dato personal» «cualquier información sobre una persona física identificada o identificable»; y como «tratamiento» a

cualquier operación o conjunto de operaciones realizadas sobre datos personales o conjuntos de datos personales, ya sea por procedimientos automatizados o no, como la recogida, registro, organización, estructuración, conservación, adaptación o modificación, extracción, consulta, utilización, comunicación por transmisión, difusión o cualquier otra forma de habilitación de acceso, cotejo o interconexión, limitación, supresión o destrucción.

Además, el apartado 15 del citado artículo, señala que se considerarán «datos relativos a la salud» los datos personales que hagan referencia a la salud física o mental de la persona, incluida la prestación de servicios de atención sanitaria, siempre que revelen datos sobre su estado de salud.

De lo anterior puede concluirse que, sin lugar a dudas, los datos obtenidos por las empresas mediante los medios de control utilizados para evitar la propagación del SARS-CoV-2, como pueden ser la temperatura corporal de la persona trabajadora, la realización de test que requieren mucosas o muestras de sangre, y otros cuyo objetivo es determinar la existencia de síntomas compatibles con la COVID-19 suponen un tratamiento de datos relativos a la salud y, por lo tanto, de datos de carácter personal del trabajador protegidos por el RGPD.

En todo caso, el art. 6.1 RGPD establece las situaciones en que ese tratamiento de datos de carácter personal será licito. Así, recoge que, para que el tratamiento de datos sea lícito, deberá cumplir, al menos, una de estas condiciones: 
a) contar con el consentimiento del interesado para el tratamiento de sus datos personales; b) que sea necesario para la ejecución de un contrato en el que el interesado es parte; c) para el cumplimiento de una obligación legal aplicable al responsable del tratamiento; d) que sea necesario para proteger intereses vitales del interesado o de otra persona física; e) que sea necesario para el logro de un interés público; y f) cuando sea necesario para satisfacer el interés del responsable del tratamiento o de un tercero, con condiciones especiales.

De todas las situaciones recogidas en el precepto señalado, el tratamiento de datos de salud del trabajador, relacionados con el SARS-CoV-2, podrá realizarse de manera lícita. En primer lugar, dicho tratamiento podrá realizarse al amparo del art. 6.1.c, ya que los datos se recaban, como se ha señalado anteriormente, para cumplir con la obligación legal del empresario de proteger la seguridad y salud de todos los trabajadores a su servicio. Por otra parte, también podría ampararse en los apartados d) y e) del citado artículo, pues en la actual situación de emergencia sanitaria y de lucha contra la pandemia, es necesario conocer estos datos para proteger un interés vital, tanto del interesado como de terceros e, igualmente, se persigue el logro de un interés público que es evitar la propagación del virus en la sociedad.

En todo caso, y como señala el art. 6.3 RGPD, cuando el tratamiento se realice al amparo de lo establecido en las letras c) y e) señaladas anteriormente - para el cumplimiento de una obligación legal empresarial, como es la protección de datos o para el logro de un interés público, la base del tratamiento deberá estar recogida en una norma legal de la Unión Europea o del país donde se realice el tratamiento; cuestión que también quedaría cubierta en esta situación, pues la propia normativa preventiva prevé la obligación empresarial de proteger la seguridad y salud de los trabajadores_- En todo caso, la finalidad del tratamiento deberá ser la que establezca esta normativa, sin poder realizarse con ningún otro objetivo que aquel previsto en la misma.

Puesto que se trata, como ya se ha señalado, de un dato relativo a la salud, estos datos serán objeto de una especial protección por parte de la normativa. Así, el art. 9.1 RGPD establece la prohibición de tratar datos relativos a la salud de las personas; a excepción de los supuestos recogidos en su apartado segundo. En concreto, se permite el tratamiento de datos relativos a la salud, como es el caso, cuando: a) el interesado haya prestado su consentimiento, otorgado con las condiciones establecidas en el art. 7 RGPD; b) el tratamiento sea necesario para que el responsable de tratamiento cumpla con sus obligaciones legales en el ámbito laboral; c) siempre que sea necesario para proteger intereses vitales del interesado y de terceros; d) si el tratamiento se realiza en el ámbito de las actividades legítimas de una entidad sin ánimo de lucro y solo implique a los miembros de la misma en activo; e) si son datos que el interesado ha hecho públicos; f) si es necesario para ejercer acciones judiciales; g) si es necesario por razones de un in- 
terés público esencial; h) es necesario para fines relacionados con medicina preventiva o laboral; i) el tratamiento sea necesario pro razones de interés público en el ámbito de la salud pública "como la protección frente a amenazas transfronterizas graves para la salud»; y j) cuando sea necesario con la finalidad de archivo de interés público, así como otras actividades de investigación y fines estadísticos.

De todas las excepciones a la prohibición del art. 9.1 RGPD señaladas, el tratamiento de datos de salud del trabajador con el objetivo de frenar la expansión del SARS-CoV-2 en la sociedad y luchar contra la pandemia, encaja en varios supuestos.

En su dimensión relacionada con el ámbito laboral, en tanto que se trata de obtener estos datos mediante la realización de reconocimientos médicos en el trabajo, el apartado b del art. 9.2 RGPD señala que se podrá realizar tratamiento de datos de salud en la empresa cuando sea necesario "para el cumplimiento de obligaciones y el ejercicio de derechos específicos del responsable del tratamiento o del interesado en el ámbito del Derecho laboral y de la seguridad y protección social». Por otra parte, el art. 9.2.h establece, de manera explícita, la legitimidad del tratamiento de datos cuando se realice con "fines de medicina preventiva o laboral, evaluación de la capacidad del trabajador, diagnóstico médico, prestación de asistencia o tratamiento de tipo sanitario o social o gestión de los sistemas y servicios de asistencia sanitaria y social».

Además, en la dimensión social de la pandemia, el apartado g) del señalado artículo establece que será posible el tratamiento de datos de salud cuando sea necesario "por razones de un interés público esencial, sobre la base del Derecho de la Unión o de los Estados miembros, que debe ser proporcional al objetivo perseguido, respetar en lo esencial el derecho a la protección de datos y establecer medidas adecuadas y específicas para proteger los intereses y derechos fundamentales del interesado».

La propia AEPD ha señalado que, las actuales circunstancias, justifican el tratamiento de datos personales, incluida la salud del trabajador, pues en situaciones como las recogidas por el art. 9.2 RGPD, el Reglamento busca «dar mayor libertad a los responsables del tratamiento en caso de necesidad para salvaguardar intereses vitales de los interesados o de otras personas físicas, intereses públicos esenciales en el ámbito de la salud pública o cumplimiento de obligaciones legales», encontrándonos ante una circunstancia excepcional en la que, como se ha señalado anteriormente, debe primar la protección de la salud pública (AEPD-Informe, 2020:4).

Aunque el propio RGPD no concreta el alcance del concepto de «interés público», el Parlamento Europeo y el consejo, en la Decisión n.o 1082/2013/ 
UE, de 22 de octubre de 2013, sobre las amenazas transfronterizas graves para la salud, definieron «amenaza transfronteriza grave para la salud» como

una amenaza para la vida u otro grave peligro para la salud de origen biológico, químico, ambiental o desconocido que se propaga o implica un riesgo significativo de propagarse a través de las fronteras nacionales de los Estados miembros y que puede requerir coordinación a nivel de la Unión para garantizar un nivel elevado de protección de la salud humana.

Con este antecedente, se entiende que un interés público en relación con la salud pública será aquel que tenga como finalidad directa la "prevención de un riesgo grave para la salud de la población», incluyendo entre estos riesgos las enfermedades o el control de epidemias y su propagación (Beltrán Aguirre et al., 2017:9).

Por todo lo anterior, queda justificado el tratamiento de datos relacionados con la salud del trabajador por parte de la empresa, pues el RGPD legitima dicho tratamiento, tanto como necesidad para dar cumplimiento a la obligación general de seguridad del empresario como en pro del interés general de proteger la salud pública y evitar, mediante la adopción de los medios necesarios, la expansión del SARS-CoV-2.

\section{Garantías que respetar en el tratamiento de datos personales: una especial referencia a los datos obtenidos a través de reconocimientos médicos para la detección del SARS-CoV-2 en la empresa}

Como se ha señalado, la normativa en materia de protección de datos contiene salvaguardas y reglas que permiten el legítimo tratamiento de datos personales, relativos a la salud del trabajador, en la lucha contra el SARS-CoV-2. Además, ninguno de los documentos normativos publicados durante el estado de alarma ha incluido cláusulas relacionadas con la protección de datos de carácter personal, por lo que el RGPD se encuentra, en estos momentos, plenamente vigente. Así lo ha manifestado también la AEPD al señalar que «el tratamiento de los datos obtenidos a partir de las tomas de temperatura debe respetar la normativa de protección de datos»(AEPD-FAQs, 2020:4).

Por todo ello, el marco jurídico de partida es el mismo que en cualquier otra situación que suponga el tratamiento de datos relativos a la salud del trabajador. Lo que genera conflicto es la dificultad de mantener las garantías recogidas en la normativa sobre protección de datos en la actual situación de la emergencia sanitaria.

Debe tenerse en cuenta que, al tratarse de datos relativos a la salud de las personas, son datos personales sensibles, pues no solo se trata de un dato de sa- 
lud en sí mismo, sino que «a partir de él, se asume que una persona padece o no una concreta enfermedad, como es la infección por coronavirus» (AEPD-Comunicado, 2020:1).

Para garantizar el adecuado tratamiento de los datos relativos a la salud del trabajador, este quedará supeditado, siempre, al interés público y a la protección de la salud pública, así como al cumplimiento de la obligación general del art. 14 LPRL relativa a la protección de la seguridad y salud de los trabajadores en el medio laboral; siendo este el objetivo que legitima el tratamiento, y no el uso de estos datos para cualquier otra finalidad. Igualmente, deben aplicarse todos los principios recogidos en el art. 5 RGPD, que establece que el tratamiento de datos personales estará limitado por el principio de licitud, lealtad y transparencia, la finalidad, la minimización de los datos, con exactitud, con limitación del plazo de conservación y respetando la integridad y la confidencialidad de estos.

Las próximas líneas, buscarán dar respuesta a como mantener el equilibrio entre la adopción de medidas dirigidas al control de la epidemia, especialmente en los centros de trabajo, dando cumplimiento los principios recogidos en el RGPD para el tratamiento de datos personales y, específicamente, de datos especialmente protegidos como son los relativos a la salud del trabajador.

\subsection{Licitud, lealtad y transparencia en el tratamiento de datos de carácter personal}

El art. 5.1 RGPD, establece, en primer lugar, que los datos deberán ser tratados de manera «lícita, leal y transparente». Así pues, la toma de temperatura a los trabajadores debe respetar el principio de legalidad, es decir, deberá estar amparado en una de las causas que legitiman el tratamiento de datos personales recogidas en el arts. 6.1 y 9.2 RGPD, pues, en ningún caso, en la actual situación que se atraviesa, podrá considerarse que basta con el consentimiento del interesado, ya que el interesado no puede negarse a la realización de la toma de temperatura, puesto que supone la imposibilidad de acceder al centro de trabajo. Por ello, podría considerarse que el consentimiento no es libre y, por tanto, estaría viciado. Esto no supone un problema en la práctica, pues como se ha visto, el tratamiento de datos relativos a la salud del trabajador encuentra legitimación en los supuestos previstos por el art. 9.2 RGPD y la propia normativa laboral permite la realización de reconocimientos médicos de carácter obligatorio en aras de proteger la seguridad y salud del propio trabajador y de terceros.

Igualmente, se deberá respetar el principio de lealtad en el tratamiento de datos, "lo que significa que está prohibido obtener datos mediante engańo, con deslealtad o de forma no lícita» (Goñi Sein, 2018:59). Este principio se sustenta en el deber de información previa, por lo que se deberá informar a los trabajadores sobre la prueba a realizar, en este caso la toma de temperatura, y el obje- 
tivo perseguido con la misma, aun cuando no sea necesario contar con su consentimiento para la realización. Como se ha visto anteriormente, esta cuestión o límite al tratamiento de datos relativos a la salud del trabajador también está recogida en la LPRL, pues aun tratándose de reconocimientos médicos de carácter obligatorio, el empresario debe informar de la prueba a realizar y el objetivo perseguido con la misma, con el objetivo de salvaguardar el derecho a la intimidad del trabajador.

Por último, el art. 5.1.a RGPD exige atender al principio de transparencia, directamente conectado con la necesidad de información previa a la realización de la prueba (STC 39/2016, VP II.b). Por tanto, y como señala Goñi Sein (2018:59),

el derecho de información de los interesados cumple dos finalidades: por un lado, que el afectado pueda prestar válidamente su consentimiento (específico, informado e inequívoco) para que se traten sus datos personales y, por otro, que el afectado pueda ejercer los derechos de acceso, rectificación, limitación al tratamiento, supresión, portabilidad y oposición que la normativa reconoce a los interesados.

Así, para que el tratamiento de datos relativos a la salud del trabajador sea válido, deberá informarse con carácter previo a su realización, de las pruebas que van a realizarse y el objetivo perseguido por las mismas. Igualmente, se informará sobre el marco jurídico que ampara la realización de estas pruebas con carácter obligatorio, haciendo referencia tanto al art. 22 LPRL como al RGPD. Por último, deberá informar de la posibilidad del trabajador de ejercer los derechos que le reconoce la normativa en materia de protección de datos y, específicamente, sobre los de acceso, rectificación, limitación del tratamiento, supresión, portabilidad y oposición.

\subsection{La finalidad como límite al tratamiento de datos personales}

En segundo lugar, el art. 5.1.b RGPD establece el límite de la finalidad para el tratamiento de datos, es decir, que estos sean «recogidos con fines determinados, explícitos y legítimos, y no sean tratados ulteriormente de manera incompatible con dichos fines». Tal como señala Goñi Sein (2018:72), «la conexión entre recogida-tratamiento de datos y finalidad es un elemento fundamental del derecho a la protección de datos».

Este principio supone que los datos relativos a la salud de los trabajadores, como por ejemplo la temperatura, solo pueden obtenerse con la finalidad concreta de detectar contagios y evitar la propagación del virus en el centro de trabajo, es decir, el acceso de la persona contagiada al centro de trabajo. La finalidad debe estar «claramente definida antes del inicio» (GOÑI SEIN, 2018:69), es decir, antes de realizar la prueba a los trabajadores, y el uso de estos datos para cualquier otra finalidad deslegitimaría su tratamiento. 
Por tanto, solo será posible el tratamiento de datos relativos a la salud de los trabajadores cuando el fin sea legítimo y el tratamiento necesario para lograr el objetivo perseguido. Debe tenerse en cuenta, igualmente, que «la finalidad, por sí sola, no justifica el tratamiento de datos», puesto que es un principio tan genérico que podría desvirtuar la legitimidad de este. En todo caso, para que no se vulnere el principio de finalidad respecto al tratamiento de datos de los trabajadores, se deberá ponderar adecuadamente el impacto que el tratamiento de datos supone en otros derechos de las personas trabajadoras, basándose siempre en los criterios señalados por las autoridades sanitarias y en la magnitud del riesgo que se pretende evitar. En el supuesto concreto que abordamos, se debería poner en valor la protección de la salud pública y de la de los trabajadores, por un lado, frente al derecho a la intimidad de estos por otro.

Como ya se ha señalado anteriormente, el derecho a la intimidad, como derecho fundamental está especialmente protegido por nuestra normativa. Sin embargo, y tal como ha señalado el Tribunal Supremo en su sentencia de 21 de enero de 2019, en su FD Quinto, apartado 3, «los derechos fundamentales no son ni ilimitados ni absolutos", por lo que pueden ser sometidos a restricciones «motivadas por las obligaciones que el texto constitucional atribuye a los poderes públicos, por un lado, y a los particulares, de otro» (Conde Ortíz, 2005:31). Así, señala la Sala que

el derecho fundamental a la intimidad personal puede ceder ante otros derechos y bienes constitucionalmente relevantes, siempre que la limitación que haya de experimentar esté fundada en una previsión legal que tenga justificación constitucional, se revele necesaria para lograr le fin legítimo previsto y sea proporcionada para alcanzarlo y sea, además, respetuosa con el contenido esencial del derecho.

Aun con todo ello, la propia AEPD ha señalado que «no se puede tomar un dato de salud de una persona y tratarlo espontáneamente por cualquier gestor de un lugar público simplemente porque crea que es lo mejor para sus clientes o usuarios» (AEPD-Tecnologías, 2020:12), puesto que, de hacerlo, existe un riesgo de difusión pública de datos de salud del interesado. De este modo, y aunque la restricción del derecho a la intimidad está amparada en la necesidad de controlar la emergencia sanitaria, se deberán respetar una serie de garantías dirigidas a proteger, en la medida de lo posible, la intimidad del interesado.

Dicho de otro modo, si bien es cierto que en la actualidad las autoridades sanitarias recomiendan tomar medidas excepcionales para el control de la epidemia, no será procedente hacerlo en una empresa en la que los trabajadores no tienen contacto entre ellos por estar a una distancia superior a dos metros, o en la que están separados entre ellos por mamparas que aseguran la contención de la expansión del virus. Solo cuando no sea posible adoptar medidas preventivas 
suficientes de aislamiento y distanciamiento social entre las personas trabajadoras será procedente realizar tomas masivas de temperatura a los empleados.

Por último, en relación con la finalidad debe tenerse en cuenta que, en caso de que los datos sean almacenados para su posterior tratamiento, ese uso posterior no podrá ser diferente a la finalidad de origen, salvo que se trate de un tratamiento "compatible con el fin para el que se recogieron inicialmente los datos personales», tal como establece el art. 6.4 RGPD, respecto a la licitud del tratamiento.

\subsection{La minimización del tratamiento de datos de carácter personal}

El art. 5.1.c RGPD establece que los datos deberán ser «adecuados, pertinentes y limitados a lo necesario en relación con los fines para los que son tratados (minimización de datos)». Este principio está directamente vinculado a la finalidad, puesto que implica que la información que se extraiga con las pruebas realizadas no solo debe encajar en uno de los supuestos previstos por la normativa, sino que, además, debe ser adecuada y proporcionada a esa finalidad que se pretende conseguir.

A este respecto, Goñi Sein (2018:74) señala que «existe una prohibición de utilizar medios que comporten tratamiento de datos cuando la finalidad se puede alcanzar por otros medios», por lo que se deberán buscar medidas alternativas, que no requieran tratamiento de datos para lograr el fin perseguido. En la actual situación, resulta imposible encontrar una herramienta que permita comprobar la existencia de sintomatología compatible con la COVID-19 sin realizar tratamiento de datos de salud del trabajador, pues en el momento en que se conoce la posible infección, se tratará de un dato relativo a la salud del trabajador. Por ello, con relación a este principio será posible el tratamiento de datos, pero deberá seleccionarse aquella prueba que resulte proporcional al riesgo que se pretende evitar, la expansión del SARS-CoV-2, seleccionando para ello aquella que resulte menos intrusiva en el ámbito reservado de la intimidad personal.

De nuevo, esta limitación también está recogida en el art. 22 LPRL, donde, tal como se ha señalado anteriormente, se establece que la prueba a realizar deberá resultar proporcional, por ser la menos intrusiva con relación al objetivo perseguido; en este caso, evitar la propagación del virus entre la plantilla y colaborar con las autoridades sanitarias en el control de la pandemia.

Debe recordarse que, en la actual situación, las pruebas que se están practicando son de dos tipos: por una parte, la toma de temperatura, con el fin de detectar sintomatología compatible con la COVID-19 y proceder al aislamiento del caso sospechoso y, en segundo lugar, la realización de pruebas serológicas y PCRs para determinar si realmente la sintomatología se debe al contagio por COVID-19 o a otras causas. Puesto que las segundas requieren de la toma de 
muestras biológicas para la realización de la prueba, resultarán más intrusivas, y no deberán ser utilizadas de forma masiva por las empresas.

Respecto a la toma de temperatura de los trabajadores, esta prueba puede realizarse mediante termómetros o a través de cámaras infrarrojas de medición de temperatura. La propia AEDP ha señalado que la toma de temperatura con un termómetro resulta menos intrusiva que mediante una cámara de infrarrojos, pues estas cámaras, además de tomar la temperatura tienen un sistema de reconocimiento facial para discriminar a las personas del resto de objetos de la imagen, lo que supondría una intrusión mayor en la esfera íntima de la persona y resultaría, por tanto, menos proporcional respecto a la finalidad perseguida: detectar la presencia de sintomatología compatible con la COVID-19 entre los trabajadores (AEPD-Tecnologías, 2020:11 y ss.).

Por todo lo anterior puede concluirse que, con objeto de respetar el principio de la finalidad, se deberá seleccionar aquella prueba, entre todas las posibles, que resulte menos intrusiva respecto al derecho a la intimidad del trabajador; que en este caso sería la toma de temperatura mediante un termómetro. Igualmente, para que se respete el principio de finalidad y proporcionalidad recogidos en la LPRL y el RGPD, se deberán tener en cuenta las características de la empresa, así como el modo de organizar el trabajo en la misma para determinar si la realización de estas pruebas es necesaria para el control de la pandemia o, por el contrario, resulta una medida excesiva.

Sin embargo, y aun con todo lo anterior, la AEPD advierte de que la aplicación de las medidas estará supeditada a las instrucciones de la autoridad sanitaria y a la justificación de su necesidad para contribuir de manera eficaz a evitar la propagación del virus y siempre respetando el resto de las cuestiones, relativas a los límites y garantías específicos para el tratamiento de datos de este tipo (AEPD-Comunicado, 2020:1).

\subsection{La exactitud de los datos como garantía de protección del derecho a la intimidad y a la protección de datos de carácter personal}

El apartado d) del art. 5.1 RGPD establece el principio de exactitud en los datos tratados. En concreto, dice que los datos deberán ser «exactos y, si fuera necesario, actualizados»; para lo que se deberán adoptar medidas «para que se supriman o rectifiquen sin dilación los datos personales que sean inexactos con respecto a los fines para los que se tratan».

Con relación a la posible toma de temperatura de los trabajadores al acceder al centro de trabajo, el principio de exactitud implica que los medios utilizados para la medición de la temperatura de los trabajadores deberán ser adecuados y fiables, por lo que deberán usarse exclusivamente dispositivos homologados y diseñados para la finalidad perseguida. 
Además, para asegurar su correcto uso y, por tanto, la exactitud de los datos obtenidos, así como para dar cumplimiento a lo establecido en el art. 22.6 LPRL, el personal a cargo de su realización deberá ser "personal sanitario con competencia técnica, formación y capacidad acreditada», por lo que deberán recibir información y formación suficiente para ello con carácter previo a la aplicación de esta medida en la empresa.

Por tanto, deberá ser el personal sanitario del servicio de prevención de la empresa quien se encargue de la realización de la prueba, así como de determinar cuándo un resultado es suficiente para proceder al aislamiento del trabajador $y$, por tanto, no permitirle la entrada en el centro por suponer un riesgo para el resto de los compañeros y cuando no. Debe tenerse en cuenta, además, que la sintomatología de la COVID-19 se muestra variable y de muy diversa tipología, por lo que, aunque la fiebre o febrícula es un indicador claro de la presencia del virus, pueden presentarse síntomas distintos a este sin ir acompañados de fiebre o febrícula, como puede ser la falta de olfato.

Las especiales características de este virus a la hora de manifestar síntomas hace más necesario si cabe, que los reconocimientos médicos sean realizados por personal sanitario formado a tal efecto, con el objetivo de que resulten eficaces en la lucha contra la expansión de la pandemia en el medio laboral.

\subsection{La limitación en el plazo de conservación}

El art. 5.1.e RGPD establece que los datos de carácter personal no deberán ser mantenidos durante más tiempo del necesario para la finalidad perseguida con el tratamiento, permitiendo su conservación posterior cuando «se traten exclusivamente con fines de archivo en interés público, fines de investigación científica o histórica o fines estadísticos» respetando, en todo caso, las garantías al tratamiento recogidas en el art. 89 RGPD para los fines señalados.

Por tanto, los datos de carácter personal deberán eliminarse en cuanto se haya dado cumplimiento a la finalidad perseguida; en este caso, determinar si el trabajador presenta sintomatología compatible con la COVID-19 o no.

En relación con la toma de temperatura de los trabajadores, puesto que la finalidad se consigue en el mismo momento en el que se realiza la prueba, los datos no podrán ser almacenados de ninguna manera, pues el almacenamiento de estos supondrá una injerencia con este principio.

Esto resulta especialmente relevante cuando la información se obtiene a través de dispositivos como cámaras infrarrojos para lecturas de temperatura, pues estás ofrecen, además, la opción de grabar y conservar los datos, e incluso reconocen el rostro humano para discriminarlo del resto de elementos de la imagen (AEPD, 2020:11), lo que entra en conflicto con el principio de limitación del plazo de conservación de los datos recogido en el art. 5.1.e RGPD. Es decir, si el 
sistema de medición de temperatura almacena los datos obtenidos, deberá prestarse especial cuidado a la finalidad, pues el almacenamiento puede no estar justificado según este principio, ya que de nada sirve tener la información sobre las variaciones de temperatura de un trabajador, sino que lo que importa es la temperatura que muestra al entrar al centro de trabajo, con el objetivo de impedir la entrada a aquellas personas que muestren este síntoma de la COVID-19.

El propio RGPD limita, así, la conservación de los datos, y «prohíbe, en consecuencia, la conservación de los datos en forma que permita la identificación de la persona, más allá del tiempo necesario para el cumplimiento del fin que justificó el tratamiento de datos» (Goñi Sein, 2018:77), lo que, en la actual situación supone que no podrán almacenarse datos sobre la temperatura de los trabajadores.

Como se ha señalado, este artículo permite su conservación exclusivamente «con fines de archivo en interés público, fines de investigación científica o histórica o fines estadísticos». Podrían, pues, almacenarse los datos obtenidos para alguno de estos fines, aunque parece que su justificación solo podrá ser suficiente cuando sea la autoridad sanitaria competente la que solicite recabar estos datos con el objetivo de realizar estudios científicos que permitan un mejor control de la pandemia.

\subsection{Integridad y confidencialidad de los datos obtenidos mediante el reconocimiento médico}

Por último, en cuanto al principio de integridad y confidencialidad de los datos, el art. 5.1.f establece que los datos deberán ser tratados

de tal manera que se garantice una seguridad adecuada de los datos personales, incluida la protección contra el tratamiento no autorizado o ilícito y contra su pérdida, destrucción o daño accidental, mediante la aplicación de medidas técnicas u organizativas apropiadas.

En atención a lo anterior, así como a lo establecido en el art. 22 LPRL respecto a la confidencialidad de los datos relativos a la salud del trabajador, siempre que sea posible se deberá mantener la confidencialidad de los datos obtenidos sobre el interesado. Sin embargo, parece razonable que, con el objetivo único de proteger la seguridad y salud de los trabajadores, la empresa —a través de su servicio médico- pueda informar sobre el hecho de que un compañero es portador del virus, siempre que se haga con el fin de evitar la propagación de este y tan solo a aquellas personas que hayan tenido contacto directo con el afectado.

Por su parte, debe recordarse aquí que el trabajador también está obligado a informar al servicio médico de la empresa, de manera inmediata, si ha estado en contacto con el virus o lo sospecha, pues el art. 29 LPRL establece la obliga- 
ción del trabajador de velar por su propia seguridad y salud y la de sus compañeros. Así lo ha entendido la AEPD haciendo referencia a la especial circunstancia que se atraviesa, señalando que no supone una injerencia en su intimidad siempre y cuando el empresario trate estos datos conforme a lo establecido en el RGPD (AEPD-Informe, 2020:4). A este respecto, la AEPD ha establecido, en un documento publicado recientemente sobre preguntas frecuentes con relación al tratamiento de datos y COVID-19 que la empresa puede preguntar al personal sobre su salud, siempre y cuando la justificación de la solicitud de información — no solo de sus trabajadores, sino también de personal externo- esté dirigida a comprobar la inexistencia de síntomas del virus, para lo que no necesitaría recabar el consentimiento del interesado, aunque, según lo establecido en la LPRL, esta información deberá recabarse a través de sus servicios médicos (AEDP-FAQs, 2020:1).

Por todo lo anterior puede concluirse que, en estos momentos, cabe la posibilidad de que la empresa informe a los trabajadores sobre el contacto con un contagiado, siempre que se haga evitando dar datos que permitan la identificación del interesado por sus compañeros.

Por otra parte, deberá tenerse especial precaución en la forma de realización de la toma de temperatura. Estos controles se están realizando, con frecuencia, en espacios públicos o compartidos de la empresa, lo que supone, como se ha señalado en el apartado anterior, que una denegación de acceso al centro desvela de manera directa, a terceras personas «que no tienen ninguna justificación para conocerlo que la persona afectada tiene una temperatura por encima de lo que se considere no relevante y, sobre todo, que puede haber sido contagiada por el virus» (AEPD-Comunicado, 2020:1).

\section{Conclusiones}

La normativa aprobada durante el estado de alarma dirigida a frenar la expansión del virus y a minimizar los efectos de la crisis sanitaria en la sociedad y economía, otorga a las autoridades sanitarias la competencia de adoptar las medidas que sean necesarias para luchar contra pandemias como la actual (AEPDInforme, 2020:6). Así, en la actual lucha contra la pandemia provocada por el SARS-CoV-2, el interés «superior» de la salud pública se muestra como elemento central, por encima de los derechos específicos de cada ciudadano, entre los que se encuentra la protección de datos de carácter personal e incluso el derecho a la intimidad recogido en el art. $18 \mathrm{CE}$. Sin embargo, esto no implica que el tratamiento de datos se pueda hacer de manera libre, pues la normativa en esta materia sigue plenamente vigente y deberá respetarse, protegiendo así, en la medida de lo posible, el derecho a la intimidad. 
En primer lugar, se concluye que es posible la realización de reconocimientos médicos a los trabajadores de manera obligatoria y masiva, dirigidas a la detección de sintomatología compatible con el SARS-CoV-2 siempre y cuando se respeten los límites a su realización establecidos en el art. 22 LPRL. Igualmente, solo resultarán proporcionales al riesgo que se pretende evitar - la expansión del virus - cuando en la empresa sea imposible tomar otras medidas preventivas como la modificación en la organización del trabajo para asegurar el distanciamiento social. Además, la empresa estará obligada, en todo caso, a adoptar el resto de medidas preventivas de protección individual, por lo que deberá dotar a los trabajadores de EPIS adecuados en función del nivel de exposición al riesgo de contagio de la COVID-19. Estos reconocimientos médicos deberán ser realizados siempre por personal médico con formación técnica adecuada, nunca por personal no sanitario.

Por su parte, el trabajador está obligado a informar al servicio médico de empresa en caso de desarrollar síntomas compatibles con la enfermedad de manera inmediata. No debe facilitar esta información al empresario, sino al servicio médico, que será quien gestione los posibles contagios y realice el seguimiento del trabajador. En todo caso, se mantendrá siempre la confidencialidad en los datos, ya sean recabados a través de una prueba o comunicados por el trabajador.

La confidencialidad de los datos obtenidos hace referencia al empresario y al resto de compañeros, pues los servicios médicos de empresa tienen la obligación de informar, en el menor tiempo posible, de los casos de COVID-19, ya sean confirmados o sospechosos, a la autoridad sanitaria competente de la comunidad autónoma donde se ubique el centro de trabajo.

En cuanto a las pruebas a realizar, será más conveniente optar por la toma de temperatura o la realización de un cuestionario sobre otros posibles síntomas, pues resulta menos invasiva que la realización de pruebas para las que se necesita una muestra biológica del trabajador, como pueden ser las serológicas o PCRs.

En tanto que, con cualquiera de los medios utilizados, se obtendrán datos relativos a la salud del trabajador, debe prestarse especial atención al tratamiento que se haga de esos datos, pues el RGPD considera que son datos especialmente protegidos. El tratamiento de estos datos en el ámbito laboral es legítimo, pues cumple, al menos, una de las condiciones del art. 6 RGPD y, además, se realiza en el marco de una de las situaciones establecidas en el art. 9 RGPD, tal como se ha señalado en el texto.

En todo caso, el tratamiento deberá respetar los principios establecidos en el art. 5 RGPD. Para ello, se deben tomar las siguientes medidas: a) la prueba a realizar consistirá, preferiblemente, en la toma de temperatura antes de acceder al centro de trabajo, y mediante termómetros, evitando el uso de cámaras térmi- 
cas. En todo caso, se seleccionará la herramienta que resulte más fiable, que deberá estar homologada y calibrada correctamente para asegurar la exactitud de los datos obtenidos; b) la prueba la realizará, siempre, personal médico formado a tal efecto, para lo que se debe contar con el servicio de prevención de la empresa; c) Se respetará la confidencialidad de los datos, por lo que, en la medida de lo posible, no se informará al resto de compañeros que hayan tenido contacto con un posible caso sobre la identidad del sospechoso. Tampoco se facilitarán datos que puedan relacionarse con la identidad de este; d) Los datos relativos a la toma de temperatura no serán almacenados, pues no está justificado su tratamiento posterior. Solo podrán ser almacenados cuando así lo solicite la autoridad sanitaria competente, en cuyo caso se facilitarán anonimizados y con el único fin de realizar estudios estadísticos que ayuden en la lucha contra la pandemia.

En definitiva, es posible la realización de pruebas para la detección de la temperatura de los trabajadores de manera generalizada y obligatoria, siempre y cuando se cuente con el criterio previo de las autoridades sanitarias que lo respalde, como es el caso. Además, se deberán cumplir las condiciones y límites establecidos, tanto en la normativa preventiva como en la de protección de datos.

\section{Bibliografía}

AEPD-Comunicado (2020). Comunicado de la AEPD en relación con la toma de temperatura por parte de comercios, centros de trabajo y otros establecimientos, AEPD. Documento disponible en: https://www.aepd.es/es/prensa-y-comunicacion/notas-deprensa/comunicado-aepd-temperatura-establecimientos

AEPD-FAQs (2020). Documento FAQs sobre el coronavirus, AEPD. Documento disponible en: https://www.aepd.es/sites/default/files/2020-03/FAQ-COVID_19.pdf

AEPD-INFORME (2020). Informe sobre la protección de datos en la actual situación de pandemia, AEPD. Documento disponible en: https://www.aepd.es/es/documento/20200017.pdf

AEPD-TeCnologías (2020). El uso de las tecnologías en la lucha contra el COVID-19. Un análisis de costes y beneficios, AEPD. Documento disponible en: https://www.aepd.es/ sites/default/files/2020-05/analisis-tecnologias-COVID19.pdf

Ministerio de SANIDAD-Instrucciones (2020). Instrucciones sobre la realización de pruebas diagnósticas para la detección del COVID-19 en el ámbito de las empresas, Ministerio de Sanidad. Documento disponible en: https://www.mscbs.gob.es/profesionales/ saludPublica/ccayes/alertasActual/nCov-China/documentos/instruccionesPruebas DiagnosticasEmpresas.pdf

Ministerio de Sanidad-Procedimiento (2020). Procedimiento de actuación para los servicios de prevención de riesgos laborales frente a la exposición al SARS-CoV-2, Ministerio de Sanidad. Documento disponible en: https:/www.mscbs.gob.es/profesionales/saludPublica/ccayes/alertasActual/nCov-China/documentos/PrevencionRRLL_ COVID-19.pdf 
Ministerio de Trabajo y Economía Social-Guía (2020). Guía para la actuación en el ámbito laboral con relación al nuevo coronavirus, Ministerio de Trabajo y Economía Social. Documento disponible en: http://www.mitramiss.gob.es/ficheros/ministerio/ inicio_destacados/Gua_Definitiva.pdf

Beltrán Aguirre, J.L.; García López, F.J. y Navarro Sánchez, C. (2017). Protección de datos personales y secreto profesional en el ámbito de la salud: una propuesta normativa de adaptación al RGPD, SESPAS.

Camas Roda, F. (2002). Las obligaciones del empresario en la normativa de prevención de riesgos laborales, Madrid: La Ley.

Conde Ortiz, C. (2005). La protección de datos personales. Un derecho autónomo con base en los conceptos de intimidad y privacidad, Madrid: Dykinson.

Fernández-Costales Muñiz, J. (2009). La vigilancia de la salud de los trabajadores, León: Eolas.

García Serrano, A. y Pedrosa Alquezar, S.I. (1999). Vigilancia de la salud de los trabajadores. Aspectos clínicos y jurídicos de los reconocimientos médicos en el trabajo, Madrid: LaLey-Actualidad.

GoÑ I SEIN, J.L. (1999). «Límites constitucionales a los reconocimientos médicos obligatorios establecidos como medida de prevención de riesgos laborales, en Revista de Derecho Social, núm. 5, pp. 49-74.

GoÑ SeIn, J.L. (2009). "Vigilancia de la salud versus protección de la intimidad del trabajador", en AAVV: Protección penal de los derechos de los trabajadores: seguridad en el trabajo, tráfico ilegal de personas e inmigración clandestina, Madrid: Edisafer, pp. 37-72.

Goñí SEIN, J.L. (2018). La nueva regulación europea y española de protección de datos y su aplicación al ámbito de la empresa (Incluido el Real Decreto-Ley 5/2018), Albacete: Bomarzo,

Goñi Sein, J.L. y Rodríguez Sanz de Galdeano, B. (2014). «El reconocimiento médico de aptitud profesional del aspirante al empleo", en AAVV: Nuevas perspectivas jurídico-éticas en el derecho sanitario, Pamplona: Aranzadi, pp. 287-322.

Marin Malo, M. (2018). La prevención del consumo de alcohol en el medio laboral. Obligaciones empresariales y medidas preventivas, Cizur Menor: Aranzadi.

Villalobos Cabrera, I. et al. (2019). Memento práctico de Prevención de Riesgos Laborales, Madrid: Francis Lefebvre. 